\title{
On the probabilistic stability of some functional equations
}

\section{Claudia Zaharia and Dorel Mihet}

\section{ABSTRACT.}

We establish stability results concerning the additive and quadratic functional equations in complete Menger $\varphi$-normed spaces by using fixed point theory. As particular cases, some theorems regarding the stability of functional equations in $\beta$ - normed and quasi-normed spaces are obtained.

\author{
DEPARTMENT OF MATHEMATICS \\ WEST UNVERSITY OF TIMIŞOARA \\ V. PÂRVAN 4, 300223 TIMIŞOARA, ROMANIA \\ E-mail address: czaharia@math.uvt.ro \\ DEPARTMENT OF MATHEMATICS \\ WEST UNVERSITY OF TIMIŞOARA \\ V. PÂRVAN 4, 300223 TIMIŞOARA, ROMANIA \\ E-mail address: mihet@math. uvt.ro
}

Received: 30.10.2011; In revised form: 27.08.2012; Accepted: 15.10.2012

2010 Mathematics Subject Classification. 54E40, 39B82, 46S50, 46 S40.

Key words and phrases. Probabilistic normed space, Hyers-Ulam-Rassias stability, fixed point theorem.

Corresponding author: Claudia Zaharia; czaharia@math.uvt.ro 